\title{
Force Chain Effect of Deep Foundation Pit Supported by Soldier Piles in the Sand-Gravel Layer
}

\author{
Jiang Xie $\mathbb{i}$, ${ }^{1}$ Xiaojia Lu, ${ }^{2}$ Jinan Wang $\mathbb{D},{ }^{1}$ Liu Yang, ${ }^{1}$ and Xiangang Han ${ }^{3}$ \\ ${ }^{1}$ School of Civil and Resource Engineering, University of Science and Technology Beijing, Beijing 100083, China \\ ${ }^{2}$ Shanghai Zhao Fa Real Estate Development Co. Ltd., Shanghai 200000, China \\ ${ }^{3}$ College of Civil Engineering, Hebei University of Engineering, Handan 056038, China
}

Correspondence should be addressed to Jiang Xie; xiejiangustb@126.com

Received 12 September 2021; Accepted 5 October 2021; Published 27 October 2021

Academic Editor: Xuepeng Zhang

Copyright () 2021 Jiang Xie et al. This is an open access article distributed under the Creative Commons Attribution License, which permits unrestricted use, distribution, and reproduction in any medium, provided the original work is properly cited.

Soldier pile support is an important tool for supporting deep foundation pits in the sand-gravel layer. However, since the sandgravel layer itself is an aggregate of particles, its noncontinuity will cause extremely complex changes in the properties of the surrounding soils during pile supporting, and the changes in the mechanical properties of the soil behind the piles can also affect the safety and stability of the pit. To study the changing pattern of the surrounding soil in the course of pile supporting, we used the numerical method to simulate an excavation in the sand-gravel layer, followed by an analysis of the movement and stress distribution of the surrounding rocks. A photoelastic experiment was carried out to simulate the excavation process and study the force chain network of the surrounding soil as well as its changing characteristics. As shown by the results, (1) during the excavation of a deep foundation pit supported by soldier piles, on the same horizontal plane, the force chain changed most dramatically at the position that was $13.8 \mathrm{~m}$ (depth of the foundation pit) away from the edge of the foundation pit; (2) during the excavation, the force chain structure of the surrounding soil changed from vertical development to both vertical and horizontal developments; when there was a hard rock layer at the bottom of the soldier piles, the supporting effect of the piles was mainly provided by the hard rock layer; (3) the free face should be reinforced, and the excavation face should be adjusted based on the underground conditions of surrounding buildings (structures).

\section{Introduction}

Excavating or supporting a deep foundation pit in the sandgravel layer is extremely difficult because of some basic issues involved, such as internal stability, external stability $[1,2]$, deformation [3-5], seepage [6], and structural form selection [7-9]. Especially for excavations in soils with multiple sand and gravel layers, problems exist such as high cost, easy deformation of the supporting structure, and adverse impacts on the environment. For instance, a foundation pit collapsed in the sand-gravel layer below a residential building in Yuxi, Yunnan Province, in 2009, causing loss of life and property. During the excavation in the sand-gravel layer at a Beijing metro station in 2010, due to design defect, noncompliant construction, the failure to monitor in time, and other reasons, the supporting structure of the deep foundation pit fell, resulting in casualties. In February 2012, cracks appeared in the foundation pit of a municipal project in Wuhan City and spread rapidly, eventually leading to the collapse of the pit. These cases remind us that further research is still needed to meet the safety requirements for excavating deep foundation pit in the sand-gravel layer.

The research on foundation pit involves physicomechanical issues at macro and micro levels. Traditionally, soil is often treated as a continuous medium from a macroscopic perspective. Terzaghi [10] pointed out the continuous medium method's limitations back in the early twentieth century. Yang [11,12] believed that the basic comprehension of rock mechanics must also begin with knowing the granular nature of rocks and soils; it is uniquely advantageous to study the force chain network structure and the evolutionary process during excavation from the particle 
point of view. Zhou $[13,14]$ used PFC to build a particle flow model for supporting the side slope of a foundation pit and adopted the discrete element method to study the pit's internal mechanical properties. The simulation of a project conducted by Jia [15] using a discrete element software showed great consistency with the monitoring data. With the discovery of photoelastic materials, photoelastic experiment has become an effective method to study the internal force chain of granular media. Kruyt and Radjai [16] mentioned that force chains can be divided into strong and weak ones and analyzed their structural forms. Kondic [17] described the force chain network with topological invariants. Meanwhile, the discrete element software PFC is also a useful instrument to study particle aggregates such as gravel soil $[18,19]$.

Scholars have conducted research on the soil of the sandgravel layer. Li [20] studied the propagation of hydraulic fractures in glutenite and concluded that the presence of gravels increased the possibility of propagation and that gravels affected the macroscopic heterogeneity of the rocks. $\mathrm{Ni}$ et al. [21] built two simplified models and compared their respective seepage by using the classic sectional combination method and considering the seepage refraction law separately. The results suggested that the model with the seepage refraction law was more practical. Through similar model tests, He [22] discovered the development pattern and structural failing process of the cracks when the tunnel was under stress, as well as the stress differences with or without the grouting reinforcement ring. Wang [23] conducted an experiment to explore the relationship between the permeation coefficient and the gravel soil porosity. The results suggested that the permeation coefficient experiment was of great practical significance for the in-depth exploration of the combined element forecast model initiated by debris flow. Chen et al. [24] studied the gravels' permeation pattern in the debris flow source regions. Zhou's [25] research revealed a relationship between the permeation coefficient of gravel soils and the initial void ratio of soil and fine particle content. Alikarami et al. [26] crushed quartz sand and other gravel particles with X-rays to form a shear zone and analyzed its characteristics. Cao [27] gives an analytical solution for the resistance of saturated soil on the side of the pile based on the normal stress assumption.

The above-mentioned studies on gravel soils certainly have significant implications. However, most studies focused on the propagation of cracks in the sand-gravel layer, the permeation pattern, and the void ratio. There are still some unresolved issues in the complexity and particularity of the sand-gravel layer. For example, if the gravel soil is taken as an aggregate of particles, how should we determine the size and direction of its internal force chains? [28-30]. For another example, when a deep foundation pit is excavated on the sand-gravel layer, is there any special effect the soil has on the supporting structure.

Judging from the noncontinuous and heterogeneous physiomechanical state of the gravel soil, the authors simulated the excavation process of a deep foundation pit in Chengdu through PFC and photoelastic experiment, emphatically analyzed the force chain network structure of the surrounding soil during the excavation in the sand-gravel layer, and quantitatively described the force chain network structure of the soil and the supporting structure.

\section{Overview of the Project}

This foundation pit was located in the Phase-II project of a hospital in Chengdu. Geological exploration data showed the site's leveling elevation on the north side of the pit was $517.25 \mathrm{~m}$ to $517.95 \mathrm{~m}$, and the excavation depth was $13.8 \mathrm{~m}$. Municipal sewage and rainwater pipelines are crossing under this section. The maximum burial depth of the pipe bottom was $-5.0 \mathrm{~m}$.

The solums on the project site consisted of the fill layer, the sandstone layer, and the pebble layer. The underground water on this site was mainly the pore water in the quaternary alluvial-diluvial sand-gravel layer. The water-bearing layers were the sandstones and the pebbles layers, the latter of which features a good water permeability. As shown by the geological exploration data, the average bulk density of the surrounding soil was $18,000 \mathrm{kN} / \mathrm{m}^{3}$, there were buildings near the foundation pit, and the additional load at the edge of the pit was about $20 \mathrm{kN} / \mathrm{m}$.

2.1. Foundation Pit Support Scheme. Since the project is quite close to the surrounding buildings, their stability should be regarded as an important issue. Soil nailing might damage the foundation of the surrounding buildings. Based on our experience in foundation pit projects in this region and considering the environmental conditions of this project, the soldier pile support was applied, with the pile diameter of $1.2 \mathrm{~m}$, the pile spacing of $2.0 \mathrm{~m}$, the pile length of $26.8 \mathrm{~m}$, and the burial depth of $13 \mathrm{~m}$.

\section{PFC Simulation of the Deep Foundation Pit Supported by Soldier Piles}

A numerical simulation analysis was performed with the PFC2D particle element software to study the microscopic mechanical characteristics, including changes of the surrounding soil during excavation, and to record the interactions between the soil and the pile.

\subsection{Establishment of the Basic Particle Flow Model}

3.1.1. Model Size. Due to symmetry, half of the simulated foundation pit was selected for the study. The model length was $46 \mathrm{~m}$ and the width was three times of the pit depth $(36 \mathrm{~m})$. The specific size is detailed in Figure 1.

3.1.2. Selection of Model Parameters. Circular particles were used for simulation. To reduce particle deformation's impact on the results, we set the stiffness and shear strength at $1 \mathrm{e} 9$ $\mathrm{N} / \mathrm{m}$. The piles were horizontally bonded, 22 balls with a radius of $0.6 \mathrm{~m}$ were used to simulate the piles, and the particles were bonded horizontally. The specific parameters are shown in Table 1. 


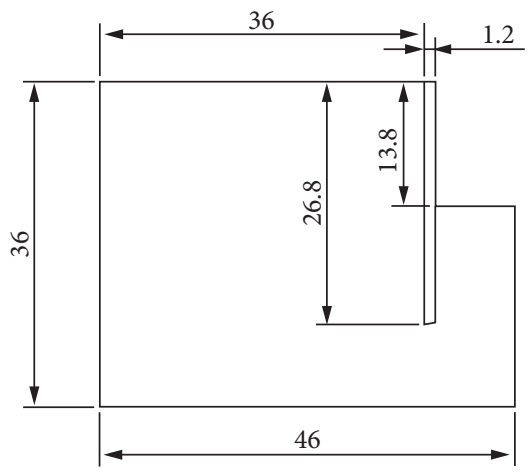

FIgURE 1: Illustration of the model.

TABle 1: Particle parameter.

\begin{tabular}{lcccc}
\hline & Stiffness $(\mathrm{N} / \mathrm{m})$ & Shear strength $(\mathrm{N} / \mathrm{m})$ & Unit weight $\left(\mathrm{kN} / \mathrm{m}^{3}\right)$ & Model type \\
\hline Soil particles & $1 \times 10^{9}$ & $1 \times 10^{9}$ & 18,000 & Stiffness model \\
Piles & $1.2 \times 10^{10}$ & $3.9 \times 10^{10}$ & 25,000 & Parallel bonding model \\
Reinforced soil & $1.5 \times 10^{11}$ & $3.9 \times 10^{11}$ & 20,000 & Parallel bonding model \\
\hline
\end{tabular}

3.1.3. Soil Simulation. The soil was formed by generating particles with a small radius, setting the density, and filling the space with the radius expansion method. Firstly, the number of particles was determined. The total area $S$ was $46 \times 36 \mathrm{~m}^{2}$, the porosity of the soil $n$ was known to be 0.72 , and the number of particles $N$ can be calculated through the following formula:

$$
N=\frac{S(1-n)}{S_{- \text {particle }}} .
$$

S-particle represents the average area of particles. The average radius of particles was $0.045 \mathrm{~m}$ and the particle area was $0.0063 \mathrm{~m}^{2}$. The number of particles was determined to be 39,000 .

50,000 particles numbered from 1 to 50,000 were generated within the area of $46 \times 36 \mathrm{~m}^{2}$ to ensure the particles can be distributed throughout the area. The particles's density was set at $18,000 \mathrm{~kg} / \mathrm{m}^{3}$, the stiffness at $1 \mathrm{e} 9 \mathrm{~N} / \mathrm{m}$, the intensity at 1 e $9 \mathrm{~N} / \mathrm{m}$, and the friction coefficient at 0.5 . The particles were allowed to fall freely after the gravity was set. The particles were expanded with the radius expansion method, and when the model reached equilibrium, ball particles above the model width of $36 \mathrm{~m}$ were deleted.

The rock layer at the pile bottom was simulated as follows: the above particles were reinforced at the range of $X$ $(0,46)$ and $Y(11,14)$ at the bottom of the model to make the soil in the coordinate region set in a parallel bonding mode. After the model became stable, the simulation of the foundation soil was formed.

3.1.4. Simulation of Boundary Conditions. The simulation of the upper load is as follows: the upper load was $20 \mathrm{kN} / \mathrm{m}$ and the model length was $46 \mathrm{~m}$, so the total upper load was calculated at $720 \mathrm{kN}$. The upper load was generated by uniformly placing high-density particles on the upper part, so 36 balls with a radius of $0.5 \mathrm{~m}$ were placed within the range of 0 to $36 \mathrm{~m}$. The density of the balls was $2.56 \mathrm{~kg} / \mathrm{m}^{3}$, so the upper load was $720 \mathrm{KN}$. The model is shown in Figure 2.

3.2. Data Monitoring. To find out the movements of the surrounding soil during the excavation in loose soil, we need to monitor the displacement of particles at the pile top and in the surrounding soil. Meanwhile, if we want to study how the force chain of the surrounding soil evolves, we need to analyze the evolution of the entire force chain diagram and set up displacement monitoring points at the following locations.

Monitoring points were set at places $0 \mathrm{~m}, 13.8 \mathrm{~m}$ (depth of the foundation pit), and $27.6 \mathrm{~m}$ (twice of pit depth) away from the supporting structure on the horizontal plane and $5 \mathrm{~m}$ and $13.8 \mathrm{~m}$ (depth of the foundation pit) away from the ground in the vertical direction. The location of the monitoring points is shown in Figure 3.

3.3. Displacement Analysis. The particles at the pile top in the model had a vertical displacement of $0.052 \mathrm{~m}$ and a horizontal displacement of $0.08 \mathrm{~m}$. The field measured data showed that the piles had a vertical displacement of $0.03 \mathrm{~m}$ and a horizontal displacement of $0.06 \mathrm{~m}$. A negligible difference was seen between the field measured data and the simulated data, indicating this simulation was a successful one and reasonable model parameters and pile bonding mode were selected.

An analysis of the displacement field reveals that foundation pit excavation is a complicated process. The displacement of the particles behind the supporting structure changed from downward movement to horizontal movement during the excavation. The displacement field of positions near the ground changed dramatically. The displacement field had little changes in the place $13.8 \mathrm{~m}$ (depth of the foundation pit) below the ground, especially in the place $26.8 \mathrm{~m}$ (depth of the supporting structure) below the 


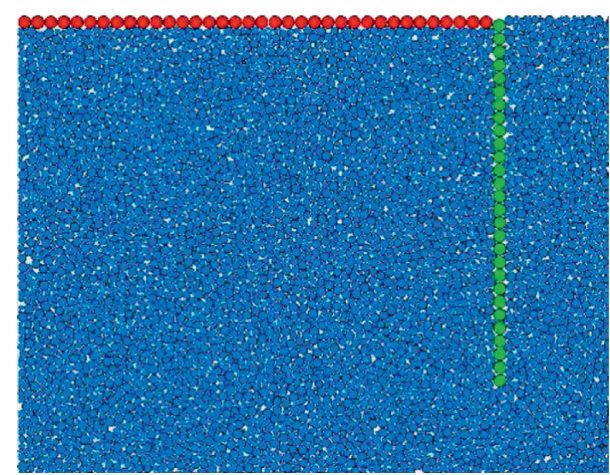

FIgURE 2: The initial state of the model.

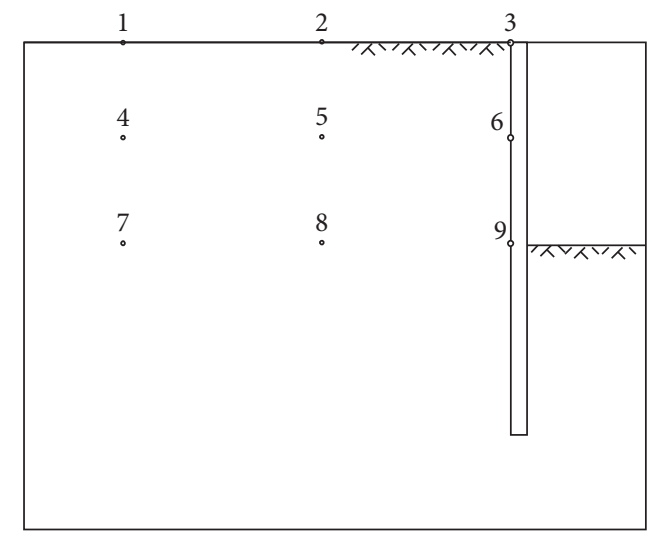

FIGURE 3: Location of monitoring points.

ground. On the same horizontal plane, the displacement field witnessed bigger changes in the place closer to the supporting structure (as shown in Figure 4).

The particle displacement of the pit surrounding rocks had the following characteristics: within the range of $13.8 \mathrm{~m}$ (depth of the foundation pit) away from the supporting structure in the horizontal direction, larger movement velocities were seen in the place closer to the supporting structure. Areas with large velocities were concentrated near the piles in the upper part of the rock layer at the bottom of the foundation pit. Within the range of $26.8 \mathrm{~m}$ (length of the supporting structure) away from the ground in the vertical direction, the particles at the bottom of the excavated foundation pit moved upward in an uplift state. This suggested that, during excavation, the largest soil displacement was seen in areas at the intersection of the excavation face and the rock layer. From the analysis results, it can be concluded that the choice of excavation interface has great influence on the soil behind pile. As a result, it is necessary to take proper measures such as drainage, reinforcement, and sectional excavation before construction to avoid foundation pit instability caused by soil movements.

3.4. Stress Monitoring. The force chain values of monitoring points are shown in Table 2 . In the same vertical direction, the force chain of the place $13.8 \mathrm{~m}$ away from the edge of the supporting structure witnessed the largest change. The

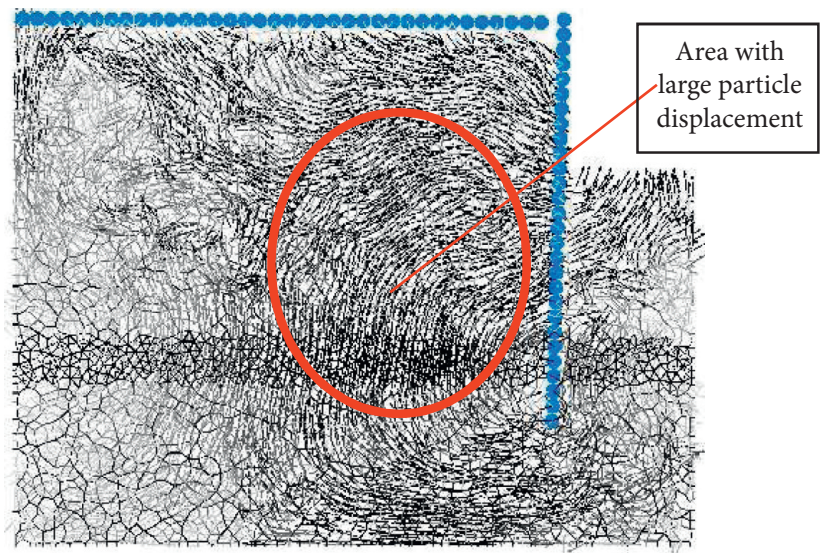

FIgURE 4: Illustration of particle displacement.

TABLE 2: Stress change values at monitoring points (unit: $\times 10^{5} \mathrm{~N}$ ).

\begin{tabular}{lcc}
\hline 1 & 2 & 3 \\
1.3 & 1.3 & 0.3 \\
4 & 5 & 6 \\
0.9 & 1.8 & 2 \\
7 & 8 & 9 \\
1.8 & 4.5 & 4 \\
\hline
\end{tabular}

internal force of the place $27.6 \mathrm{~m}$ away from the pit's edge had the smallest change during excavation.

In the same horizontal direction, the mean force chain value in the place $13.8 \mathrm{~m}$ from the ground was the largest. The stress of the lower particles was greater than that of the upper ones because the force chain had carried all the particle gravity.

The force chain value changed the most in the place $13.8 \mathrm{~m}$ away from the foundation pit. This indicated that the soil in the place $13.8 \mathrm{~m}$ from the piles had the largest stress change during excavation. From the analysis results of the monitoring points, it can also be concluded that the choice of excavation interface has a great influence on the soil behind the pile.

\section{Photoelastic Experimental Simulation on the Excavation of the Deep Foundation Pit Supported by Soldier Piles}

Judging from the noncontinuous and heterogeneous physiomechanical state of the gravel soil around the project, we simulated the excavation with a photoelastic experiment to analyze the structure and evolutionary characteristics of the force chain network and quantitatively describe the force chain structure and its changing pattern.

An appropriate similarity ratio was established based on the maximum size and load limit of the experimental machine. The model width was $760 \mathrm{~mm}$ and the length similarity ratio was taken as 47 , equivalent to the actual length of $35.72 \mathrm{~m}$. The actual formation density was $1.8 \mathrm{~g} / \mathrm{cm} 3$, the photoelastic material density was $1.2 \mathrm{~g} / \mathrm{cm}^{3}$, and the density similarity ratio was 1.5 . The soil of $36 \mathrm{~m} \times 36 \mathrm{~m}$ was simulated in a bidirectional loading and bidirectional flow device of $76 \mathrm{~cm} \times 76 \mathrm{~cm}$. The layout is as follows. The excavation 


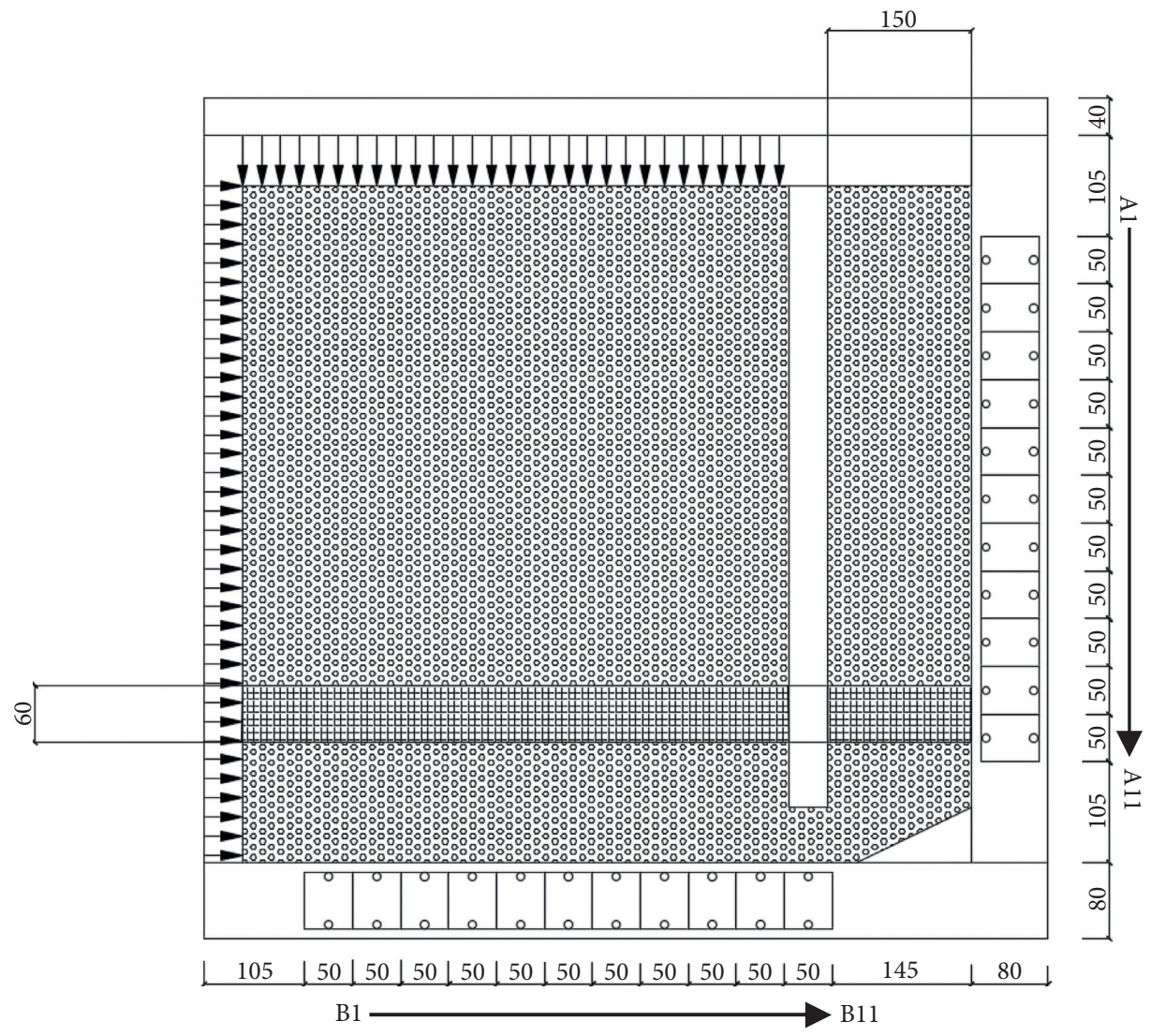

FIgURE 5: Illustration of the photoelastic experiment.

section was filled with circular particles. Square particles were laid at the bottom $(52-58 \mathrm{~cm})$ to simulate the rock layer. The pile length was $65 \mathrm{~cm}$, the depth of the foundation pit was $38 \mathrm{~cm}$, the piles were $15 \mathrm{~cm}$ away from the right discharge port, and the pile was of the same height as the particles. $70 \mathrm{~N}$ servo pressure was applied on the left side and $200 \mathrm{~N}$ servo pressure was applied on the left side of the pile top. The excavation was simulated by the discharge of circular particles from the discharge port. The schematic diagram of equipment is shown in Figure 5.

The experimental process is as follows: the excavation consists of two phases, that is, excavation and support. Limited by the experimental conditions, this paper only focused on studying the characteristics and evolutionary pattern of the force chains behind the piles in the surrounding soil during excavation. Since the size of the particle discharge port of the photoelastic device was $5 \mathrm{~cm}$, the excavation depth that can be simulated each time was $2.35 \mathrm{~m}$. The excavation process of foundation pit is shown in Table 3.

4.1. Research on Force Chain Direction. Force chain diagram of foundation pit excavation process is shown in Figures 6-9. Rose diagrams were obtained by using MATLAB to analyze and process the above force chain diagrams. For instance, $18^{\circ}$ was set as an interval. Compared with the data before excavation, the number of force chains after the excavation in the horizontal direction $\left(-9^{\circ}-9^{\circ}, 81^{\circ}-90^{\circ}\right.$, and $\left.152-170^{\circ}\right)$ reduced by 28 , or 9 in each interval on average, and reduced by 5 in the vertical direction $\left(81^{\circ}-98^{\circ}\right)$; the number of force chains in the middle direction $\left(9^{\circ}-27^{\circ}, 27^{\circ}-45^{\circ}, 45^{\circ}-63^{\circ}\right.$, $63^{\circ}-81^{\circ}, 98^{\circ}-116^{\circ}, 116^{\circ}-134^{\circ}$, and $134^{\circ}-152^{\circ}$ ) increased by 13 , or 2 in each interval on average, as shown in Figures 10 and 11. Only vertical and horizontal loads were applied in this experiment. This suggested that, in granular media, when the vertical and horizontal loads remained unchanged, the number of strong force chains was reduced in both vertical and horizontal directions during excavation, and such chains were turned towards the direction where no stress would be applied. This was because after the foundation pit was excavated in the sand-gravel layer, the crustal stress was released, and a large rebound deformation began to occur towards the free face. From this, suggestion can be made that, during the excavation of foundation pit in the soil composed primarily of loose gravels with a free face, the soil should be reinforced by grouting, steel wire mesh laying, or other means, to prevent the soil from collapsing towards the free face or the direction with little stress (the foundation pit accident in Beijing mentioned in the Introduction was caused by a similar situation).

4.2. Diagrams of Force Chains behind Piles. The following characteristics can be obtained during excavation by quantitatively extracting the force chains behind the piles: 
TABle 3: Excavation sequence.

\begin{tabular}{lcccc}
\hline & Discharge port & Propulsion depth $(\mathrm{m})$ & Equivalent excavation depth $(\mathrm{m})$ & Equivalent excavation area $(\mathrm{m})$ \\
\hline First excavation & A2 & 5 & 5 & $35.25^{2}$ \\
Second excavation & A4 & 5 & 5 & $35.25^{2}$ \\
Third excavation & A5 & 3.8 & 3.8 & $26.78^{2}$ \\
\hline
\end{tabular}

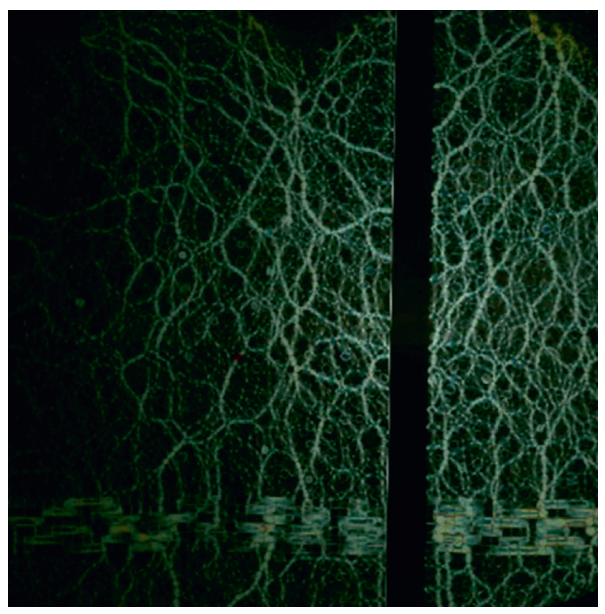

FIgURE 6: Force chains before excavation.

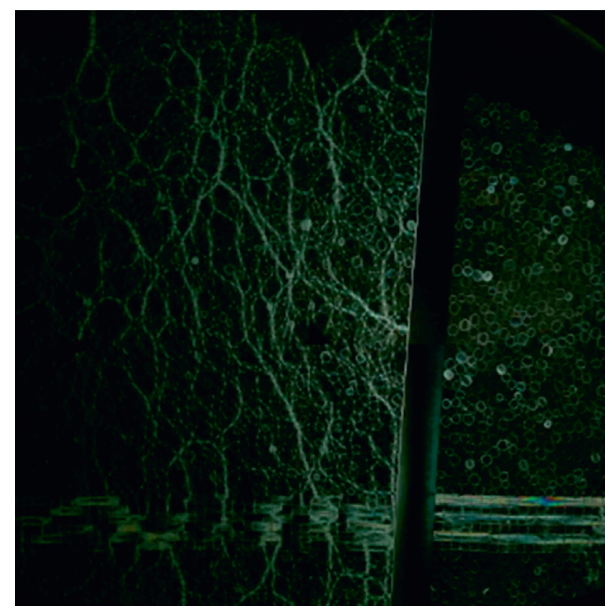

FIgURE 7: Force chains after the first excavation.

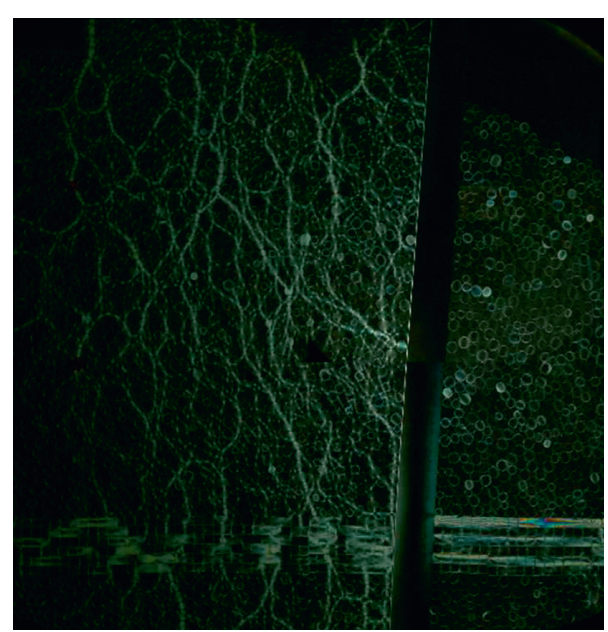

Figure 8: Force chains after the second excavation. 


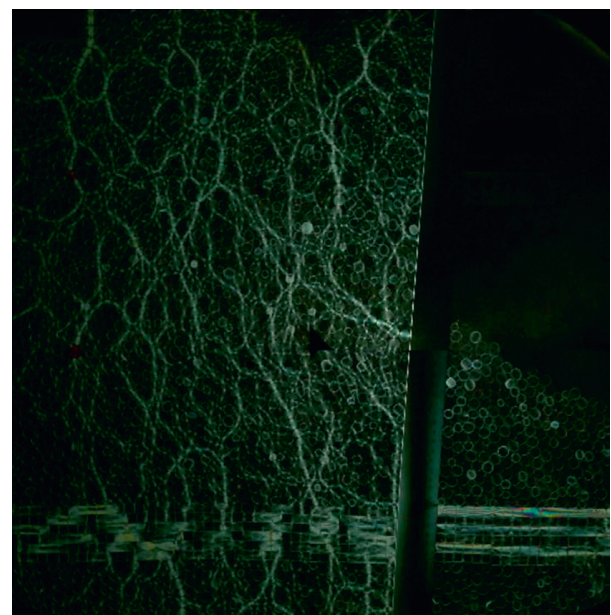

FIGURE 9: Force chains after the third excavation (excavation completed).

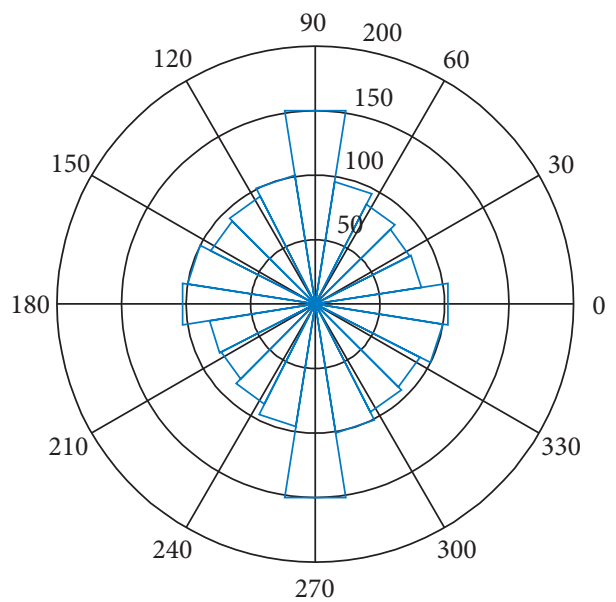

Figure 10: Rose diagram before excavation.

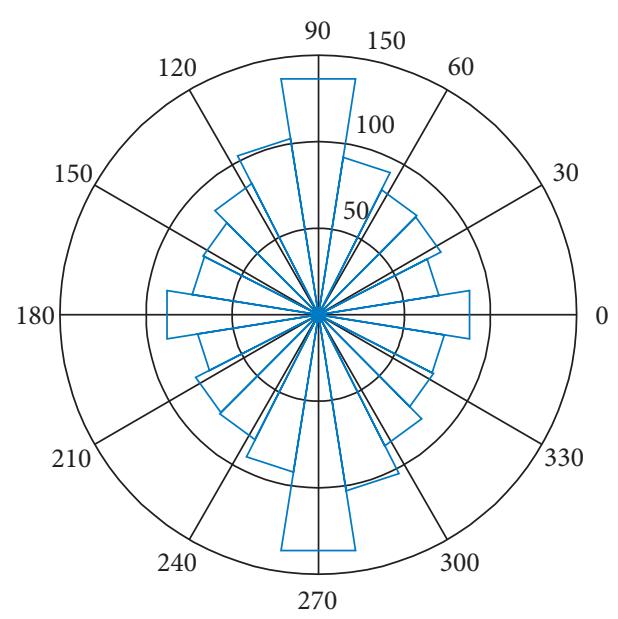

FIGURE 11: Rose diagram after excavation. 


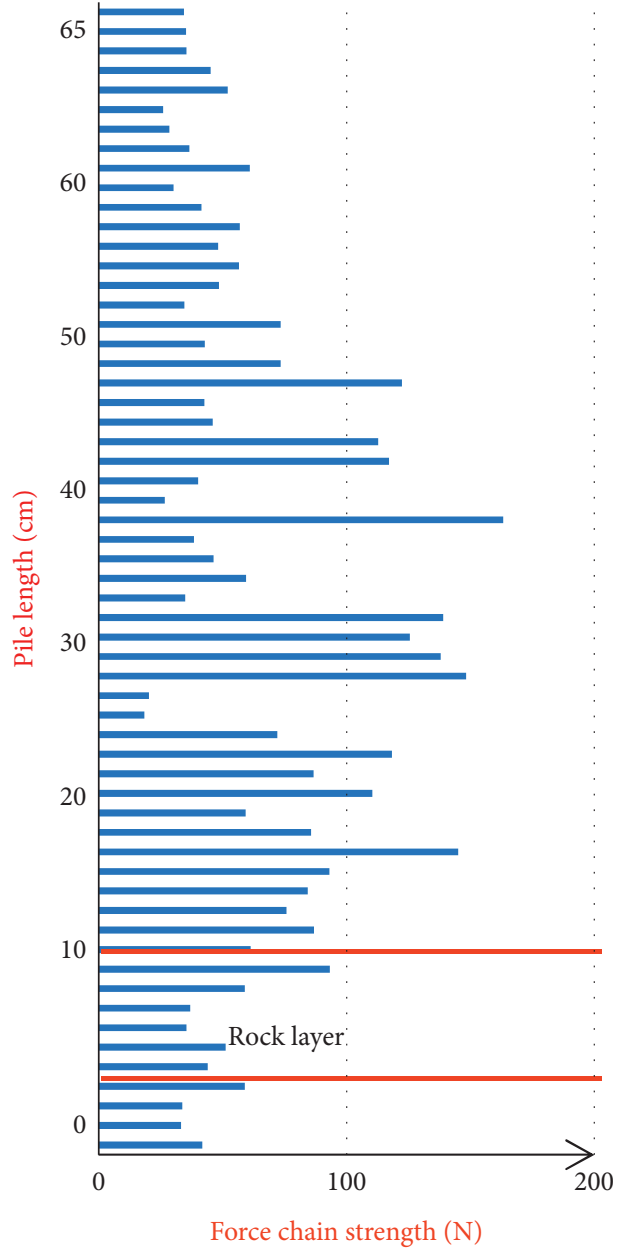

(a)

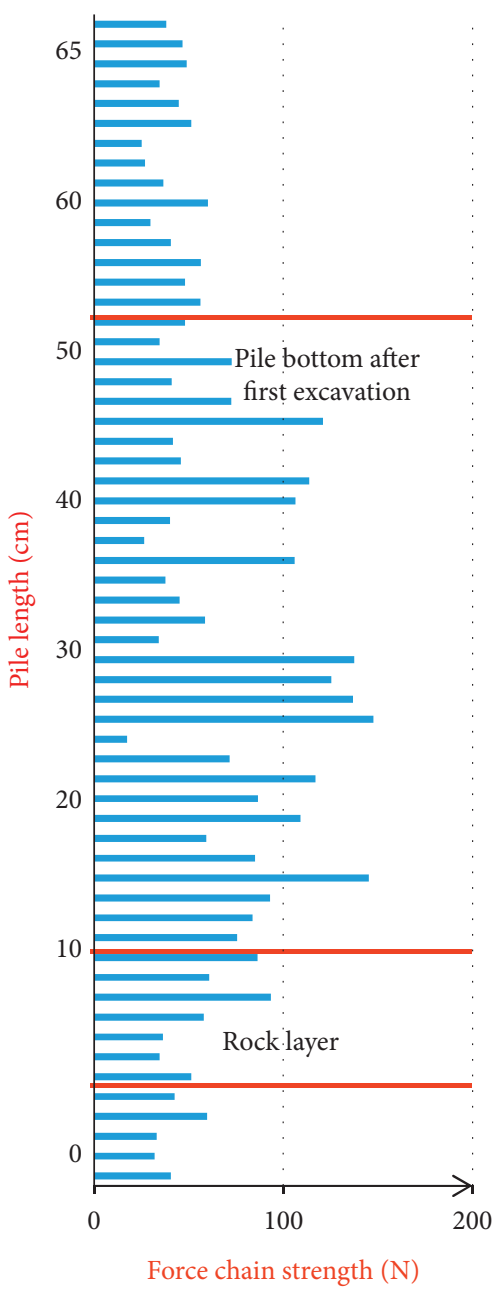

(b)

Figure 12: Continued. 


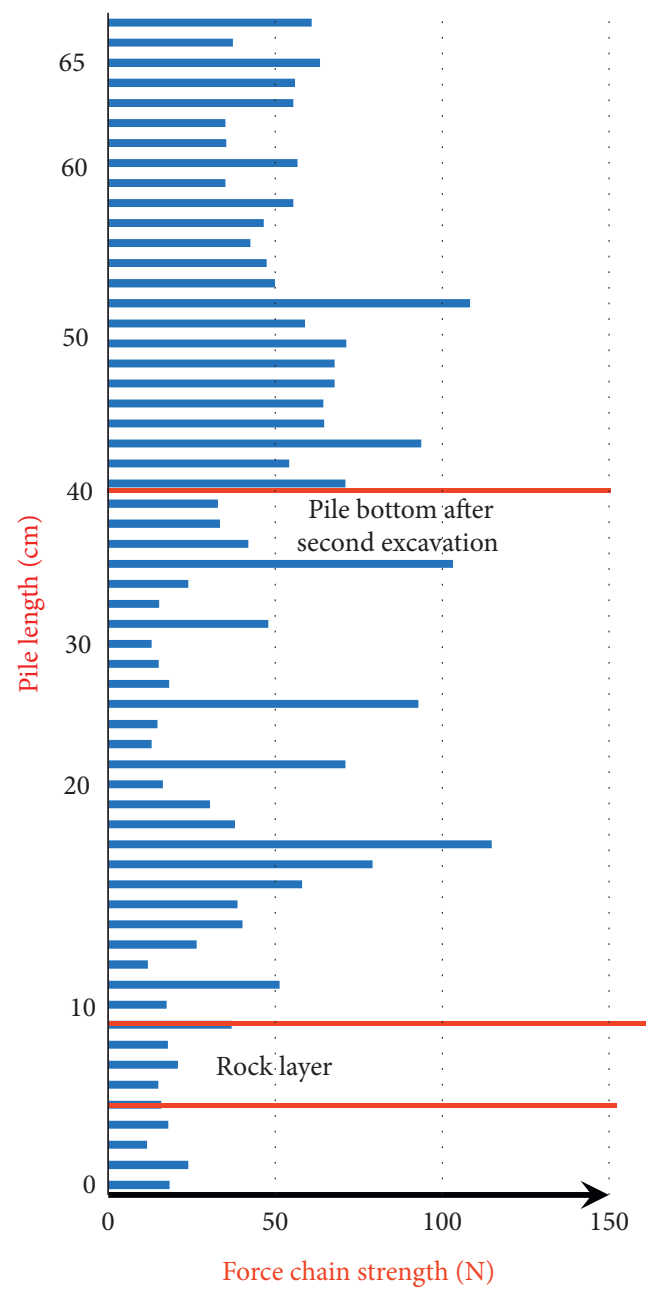

(c)

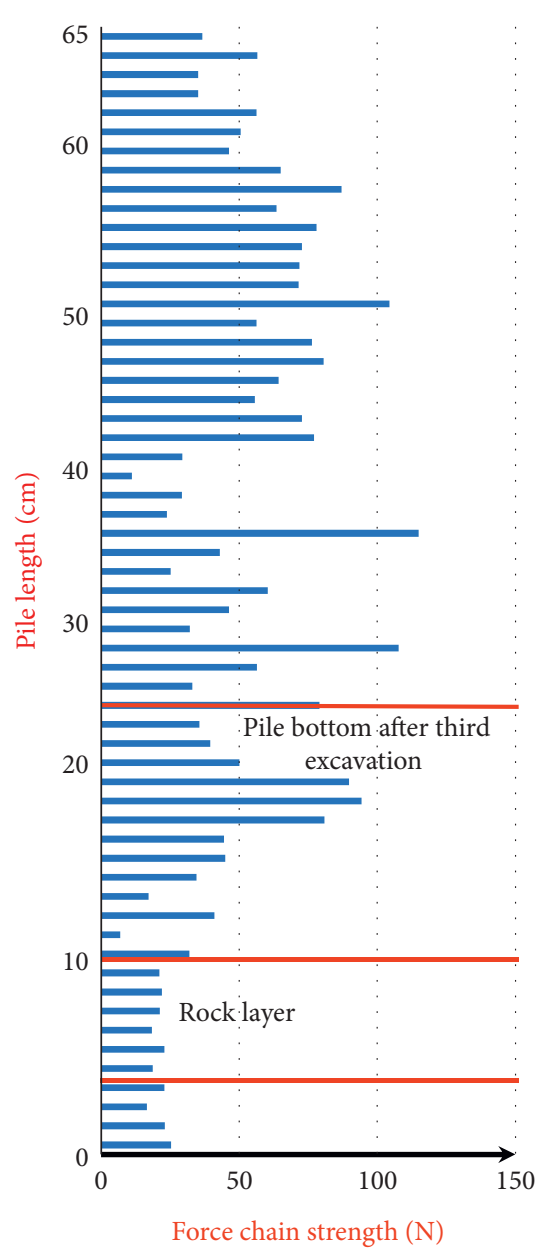

(d)

Figure 12: Size of force chains behind piles.

(1) Before excavation, the force chains took the shape of small ends and a large middle. After the second excavation, the force chains in the square particles were constantly strong, and the force chain reached the strongest in the place near the top of the square particles. As the excavation proceeded, this force chain strength basically remained unchanged and the strength was greater than that of the bottommost layer. This indicated that when there was a rock layer at the bottom, the embedding force of the piles was mostly provided by the hard rock layer near the bottom. It is thus suggested that the pile bottom should be rested on the rock layer during construction if conditions permit. Refer to Figure 12.

(2) After each excavation, in the place $1.5 \mathrm{~cm}$ above the bottom end of the excavation (corresponding to about $0.5 \mathrm{~m}$ in the actual situation), the force chain value reached the maximum within that short interval. In the meantime, we found that as excavation continued, the force chain value of the previous excavation interface remained the maximum in the short interval. This suggested that the selection of the interface bottom had continuous impacts on the surrounding soil. The excavation bottom should not be set on vulnerable planes to prevent important buildings or structures from being affected.

\section{Conclusion}

The following conclusions can be obtained by analyzing the force chains of the soils surrounding the foundation pit supported by soldier piles during excavation:

(1) The displacement field analysis showed that displacements were concentrated on the places $13.8 \mathrm{~m}$ (depth of the foundation pit) away from the supporting structure horizontally and $26.8 \mathrm{~m}$ (length of the supporting structure) vertically. Stress analysis suggested that, in the same horizontal direction, the least stress change was seen at the point $27.6 \mathrm{~m}$ away from the foundation pit. In the same vertical direction, the largest stress change was recorded at the point $13.8 \mathrm{~m}$ away from the piles. 
(2) Structural analysis of the force chain diagrams indicated that, during excavation, the force chains of the surrounding soils changed from mainly vertical development to both vertical and horizontal developments. Force chains developed more in the direction without direct stress. When excavating a foundation pit composed primarily of loose gravels, the soil should be reinforced by grouting, steel wire mesh laying, or other means, to prevent the soil from collapsing towards the free face or the direction with smaller stress.

(3) Compared to other supporting means such as bolting support, soldier pile support is often considered to have fewer disturbances to the surrounding environment. As can be seen from the simulation, the force chains within the range of $13.8 \mathrm{~m}$ changed considerably, indicating that soldier pile support also significantly impacts the surrounding environment within the range, especially on the internal stress of the underground soil. The excavation face selection dramatically influences the stress of surrounding objects, so it is suggested not to set up an excavation face on the same horizontal plane as the vulnerable object to prevent threats to neighboring pipelines and buildings (structures).

\section{Data Availability}

The datasets generated and analyzed in the current study may be obtained from the corresponding author upon reasonable request.

\section{Conflicts of Interest}

The authors declare no conflicts of interest.

\section{Authors' Contributions}

Jiang Xie conceived, designed, and performed the study. Xiaojia Lu collected and analyzed the example used in the paper. Jiang Xie, Liu Yang, and Xiangang Han wrote and revised the paper together. The authors have read and approved the final published manuscript.

\section{Acknowledgments}

This work was supported by the National Key R\&D Plan Project (2017YFC1503104).

\section{References}

[1] J. Shenghua and J. Wang, "Practice in design and construction of oversized deep foundation pit project in beijing," Geotechnical Engineering Technique, vol. 28, no. 6, pp. 278-315, 2014.

[2] L. I. A. O. Shao-ming, W. E. I. Shi-feng, Y. Tan, and J.-X. Liu, "Field performance of large-scale deep excavation in Suzhou," Chinese Journal of Geotechnical Engineering, vol. 37, no. 3, pp. 458-469, 2015.
[3] H. x Wang, "Safety factor of heave-resistant stability considering two- and three-dimensional size effects of foundation pits," Chinese Journal of Geotechnical Engineering, vol. 35, no. 11, pp. 2144-2152, 2013.

[4] L. Gu, Z. Wang, Q. Huang, G. Ye, and F. Zhang, "Numerical investigation into ground treatment to mitigate the permanent train-induced deformation of pile-raft-soft soil system," Transportation Geotechnics, vol. 24, Article ID 100368, 2020.

[5] X. Jiang, G. Dai, W. Gong, R. P. Gamage, and F. Xu, "A review of research on the shaft resistance of rock-socketed piles," Acta Geotechnica, vol. 16, no. 3, pp. 653-677, 2021.

[6] X. Q. Wang, Y. L. Cui, S. M. Zhang, S. Tao, and B. Li, "Field test on bearing characteristics of diaphragm walls under high water pressure at floodplain of Yangtze River Chinese," Journal of Rock Mechanics and Engineering, vol. 36, no. 3, pp. 773-780, 2017.

[7] R. Z. Liang, C. G. Lin, T. D. Xia, and S. M. Wu, "Analysis on the longitudinal deformation of tunnels due to pit excavation considering the tunnel shearing effect Chinese," Journal of Rock Mechanics and Engineering, vol. 36, no. 1, pp. 223-233, 2017.

[8] L. Chen, Y. Sun, and Z. Wang, "Research of finite difference method on retaining structures with internal braces in deep excavation engineering," Chinese Journal of Rock Mechanics and Engineering, vol. 35, no. S1, pp. 3315-3322, 2016.

[9] H. Wang, "A coeffient of heave-resisitant stability considering shapes and plane sizes and it application to the stability analysis of shaped excavations," Chinese Journal of Rock Mechanics and Engineering, vol. 34, no. 12, pp. 2559-2571, 2015.

[10] K. Terzaghi and R. B. Peck, Soil Mechanics in Engineering Practice, John Wiley and Sons,inc., New York, 2nd edition, 1967.

[11] Y Rong Wei, Direct Shear Experiments of Photo Elastic Granular Materials, Tsinghua University, BeiJing, China, 2009.

[12] Y. Rong-wei and C. Xiao-hui, "Direct shear experiments of photoelastic granular materials," Rock and soil materials, vol. 30, no. S1, pp. 103-109, 2009.

[13] W. Liu and J. Zhou, "Numerical simulation of particle flow code for pile under uplifting load," Chinese Journal of Geotechnical Engineering, vol. 26, no. 4, pp. 516-521, 2004.

[14] Y. Liu, J. Zhou, and J. X. Fu, "Fluid-particle coupled model for saturated sand and its application to liquefaction analysis," Journal of Hydraulic Engineering, vol. 40, no. 2, pp. 250-256, 2009.

[15] M. Jia, L. Wang, and J. Zhou, "Simulation of soil deformation due to pit excavation with particle flow code," Journal of Tongji University, vol. 37, no. 5, pp. 612-617, 2009.

[16] N. P. Kruyt, "On weak and strong contact force networks in granular material," International Journal of Solids and Structures, vol. 92, pp. 135-140, 2016.

[17] L. Kondic, A. Goullet, C. S. O’Hern, M. Kramar, K. Mischaikow, and R. P. Behringer, "Topology of force networks in compressed granular media," EPL (Europhysics Letters), vol. 97, no. 5, Article ID 54001, 2012.

[18] G. Zheng, C. X. Song, and Y. Diao, "Discrete element simulation and redundancy analysis of excavation collapse," Rock and Soil Mechanics, vol. 35, no. 2, pp. 573-583, 2014.

[19] Q. H. Chen, Discrete Element Modeling of Composite SoilNailed Wall in Soft Soil, College of Civil Engineering and Architecture Zhejiang University of Technology, Hangzhou, China, 2012. 
[20] L. I. Lian-chong, L. I. Gen, Q.-m. Meng, H. Wang, and Z. Wang, "Numerical simulation of propagation of hydraulic fractures in glutenite formation," Rock and Soil Mechanics, vol. 34, no. 5, pp. 1501-1507, 2013.

[21] C.-S. Ni, H. rui, and B. A. I. Shi-wei, "Research on seepage of large foundation pit excavation of a hydro-junction power plant," Rock and Soil Mechanics, no. 7, pp. 1819-1824, 2008.

[22] H.-J. Zhang, C. Yang, G. Wang, and M. Shu, "Experimental study on mechanical behavior nonsymmetric muli-arch tunnel in sand-cobble ground," China Civil Engineering Journal, vol. 50, no. 5, pp. 116-124, 2017.

[23] Y. Wang, Y. Zou, and R. Yuan, "Interrelated research of relationship between debris flow's trigger and permeation coefficient," Journal of Soil Erosion and Soil and Water Conservation, no. 4, pp. 77-83, 1997.

[24] N. Chen and J. Zhang, "The research of permeability on lose gravelly soil in debris flow original area," Journal of Mountain Science, no. 2, pp. 169-171, 2001.

[25] X. J. Zhou, P. Cui, and J. Li Zhan lu, "Development and application OF integrated test equipment for permeability and settlement OF gravelly soil IN triggering area OF debris flow," Chinese Journal of Rock Mechanics and Engineering, vol. 31, no. 6, pp. 1281-1289, 2012.

[26] R. Alikarami, E. Andò, M. Gkiousas-Kapnisis, A. Torabi, and G. Viggiani, "Strain localisation and grain breakage in sand under shearing at high mean stress: insights from in situ X-ray tomography," Acta Geotechnica, vol. 10, no. 1, pp. 15-30, 2015.

[27] C. Xiaolin, D. Guoliang, G. Weiming, Z. Fengxi, and X. Jiang, "Resistance of saturated soil to a laterally vibrating pile," Soil Dynamics and Earthquake Engineering, vol. 141, Article ID 106496, 2021.

[28] C. Zhoujian and J.-H. Cui, "Numerical simulation of cone penetration test by discrete element method," Chinese Journal of Geotechnical Engineering, vol. 29, pp. 1604-1610, 2007.

[29] W. Leiming, Y. Shenghua, W. Aixiang, and W. Chen, "Synergetic bioleaching of low-grade copper sulfides using mixed microorganisms and its community structure succession," Journal of Cleaner Production, vol. 245, Article ID 118689, 2020.

[30] W. Leiming, Y. Shenghua, and W. Aixiang, "Ore agglomeration behavior and its key controlling factors in heap leaching of low-grade copper minerals," Journal of Cleaner Production, vol. 279, Article ID 123705, 2020. 